установленной в административном праве, которая выражена административным наказанием в виде административного штрафа.

$$
* * *
$$

1. Налоговый кодекс Российской Федерации (часть первая) от 31.07.1998 № 146-Ф3 // Собрание законодательства РФ. № 31. 03.08.1998. Ст. 3824

2. Кодекс Российской Федерации об административных правонарушениях от 30.12.2001 № 195-Ф3 // Собрание законодательства РФ. 07.01.2002. № 1 (ч. 1). Ст. 1.

3. Бюджетный кодекс Российской Федерации от 31.07.1998 № 145-Ф3 //Собрание законодательства РФ. 03.08.1998. № 31. СТ. 3823

4. Авдеенкова М.П. Особенности развития административно-правовой ответственности в российском праве // Современное право. 2008. № 3. С.10

5. Тютина Ю.В. содержание финансово-правовой ответственности // Финансовое право. 2009. № 2. C. 8

6. Зрелов А.П. Административное расследование нарушений законодательства в области налогов и сборов: Дис. ... канд. юрид. наук. М., 2005. Цит. по: Грачева Е.Ю., Щекин Д.М. Комментарий к диссертационным исследованиям по финансовому праву. М., 2009. С. 563.

7. Салищева Н.Г. Проблемные вопросы института административной ответственности в России // Государство и право. 2005. № 1. С. 23

8. Административная юрисдикция налоговых органов: учебник / Е.А. Алехин, Л.М. Ведерников, А.М. Воронов и др.; под ред. М.А. Лапиной. М.: ВГНА Минфина России, 2012. С. 245.

9. Серков П.П. Административная ответственность в российском праве: современное осмысление и новые подходы: монография. М.: Норма, Инфра-М, 2012. С. 367

10. Финансовое право: учебник / под общ. ред. Э.Д. Соколовой; отв. ред. А.Ю. Ильин. М.: Проспект, 2019. C. 478.

11. Комягин Д.Л. Бюджетные нарушения и бюджетные меры принуждения: новации бюджетного законодательства // Реформы и право. 2014. № 2. С. 11

12. Саттарова Н.А. Меры государственного принуждения в бюджетной сфере как фактор эффективного функционирования финансовой системы // Lex russica. 2015. № 8. С. 104

13. Полякова С.А. О бюджетных мерах принуждения // Право и экономика. 2015. № 4. С. 70

14. Парыгина В.А., Тедеев А.А. Бюджетное право и процесс: Учебник. М., 2005. С. 332.

15. Бюджетное право: учебник / Н.Д. Вершило, Т.А. Вершило, О.Н. Горбунова и др.; под ред. И.А. Цинделиани. М.: Проспект, 2018. 400 с.

\title{
Соловьева С.В. ${ }^{1}$, Удычак Ф.Н. $^{2}$, Чеботарева И.Ю. ${ }^{3}$ Бюджетная ответственность как самостоятельный вид юридической ответственности: за и против
}

\author{
${ }^{1}$ Российская академия правосудия \\ (Россия, Краснодар) \\ ${ }^{2}$ Адыгейский государственный университет \\ (Россия, Майкоп) \\ ${ }^{3}$ Адыгейский государственный университет, филиал в г. Белореченске
}

(Россия, Белореченск)

doi: $10.18411 / \mathrm{j}-08-2021-140$

\section{Аннотация}

Вопрос о бюджетной ответственности является дискуссионным в наши дни. С одной стороны, споры вызывает наличие такой ответственности, с другой разногласия в определении характера бюджетных санкций, порядка их применения и состава бюджетный нарушений. Большинство ученых вполне обосновано считают наличие бюджетной ответственности видом самостоятельной юридической ответственности. Наша задача разобраться в этом вопросе, взвесив за и против.

Ключевые слова: бюджетное нарушение, бюджетная ответственность, бюджетные меры принуждения. 


\section{Abstract}

The issue of budget responsibility is debatable these days. On the one hand, the existence of such responsibility causes disputes, on the other-disagreements in determining the nature of budget sanctions, the procedure for their application and the composition of budget violations. Most scientists quite reasonably consider the presence of budget responsibility as a kind of independent legal responsibility. Our task is to understand this issue, weighing the pros and cons.

Keywords: budget violation, budget responsibility, budget enforcement measures.

В статье 306.1 Бюджетного кодекса РФ [1] закреплено: бюджетное нарушение представляет собой совершенное высшим исполнительным органом государственной власти субъекта Российской Федерации (местной администрацией) нарушение положений бюджетного законодательства Российской Федерации и иных правовых актов, регулирующих бюджетные правоотношения. Так, существуют следующие виды нарушений:

1) нецелевое использование бюджетных средств;

2) невозврат либо несвоевременный возврат бюджетного кредита;

3) не перечисление либо несвоевременное перечисление платы за пользование бюджетным кредитом;

4) нарушение условий предоставления бюджетного кредита.

В настоящее время за бюджетные нарушения вместо мер юридической ответственности применяются бюджетные меры принуждения.

В соответствии со статьей 306.2 БК РФ, бесспорное взыскание суммы средств, предоставленных из одного бюджета бюджетной системы Российской Федерации другому бюджету бюджетной системы Российской Федерации, бесспорное взыскание суммы за пользование средствами, предоставленными из одного бюджета бюджетной системы Российской Федерации другому бюджету бюджетной системы Российской Федерации; бесспорное взыскание пеней за несвоевременный возврат средств бюджета; приостановление (сокращение) предоставления межбюджетных трансфертов (за исключением субвенций) - бюджетные меры принуждения.

Бюджетные меры принуждения за совершение бюджетного нарушения применяются финансовыми органами и Федеральным казначейством на основании уведомления о применении бюджетных мер принуждения. Под названными мерами принуждения понимаются инструменты соответствующего регулирования, а также особые санкции, которые содержатся в бюджетном законодательстве, имеют превентивный эффект и служат в качестве обеспечительных мер.

Различие между мерами государственного принуждения административных правонарушений и бюджетных нарушений состоит в том, что КоАП РФ предусмотрены единовременные штрафы или дисквалификация как мера ответственности должностных лиц, а для юридических лиц - штраф в размере, кратном сумме средства от незаконно выполненной операции.

За нарушение бюджетного законодательства административные правонарушения предусматривают применение административных санкций, a соответствующие бюджетные нарушения влекут меры бюджетного принуждения. Так, ст.15.14 КоАП РФ [2] (нецелевое использование бюджетных средств) предусмотрено наложение административного штрафа на должностных лиц в размере от двадцати тысяч до пятидесяти тысяч рублей или дисквалификацию на срок от одного года до трех лет; на юридических лиц - от 5 до 25 процентов суммы средств, полученных из бюджета бюджетной системы Российской Федерации, использованных не по целевому назначению.

А ст.306.4 БК РФ (нецелевое использование бюджетных средств) влечет бесспорное взыскание суммы средств, использованных не по целевому назначению, или 
сокращение предоставления межбюджетных трансфертов (за исключением субвенций и дотаций на выравнивание бюджетной обеспеченности субъектов Российской Федерации и муниципальных образований). То есть можно сказать, что определения объективной стороны составов правонарушения, по своей сути одинаковы, но при этом установлены разные виды санкций.

Анализируя, а также сопоставляя составы бюджетных и административных правонарушений, стоит отметить следующее: правонарушения, совершаемые в бюджетной сфере, как правило, закрепляются в КоАП РФ.

Нарушение бюджетного законодательства влечет за собой уголовную ответственность. Наумов А.В. в своих трудах раскрывает понятие уголовной ответственности как меры государственного воздействия на лицо, совершившее противоправное деяние, характеризующееся признаками уголовной ответственности [7, c. 407].

Бюджетная ответственность, обладает всеми признаками юридической ответственности, и может выступать как самостоятельный вид юридической ответственности.

В то же время, финансово-правовая ответственность характеризуется следующими признаками:

— ответственность устанавливается бюджетным законодательством;

- ответственность заключается в применении специальных бюджетных санкций;

- санкции наказания применяются к лицу, совершившему правонарушение, установленное нормами бюджетного законодательства;

- основанием является бюджетное правонарушение, то есть нарушение бюджетного законодательства;

— привлечение к ответственности осуществляется в установленном порядке.

При привлечении правонарушителя к ответственности государство преследует следующие основные цели:

1. Обеспечить исполнение бюджетного законодательства;

2. Привлечь к ответственности правонарушителя;

3. Защитить имущественные интересы участников бюджетных правоотношений.

Бюджетно-правовая ответственность возникает в процессе бюджетных правоотношений как результат нарушения установленных законом правил поведения.

Многие ученые-финансисты признают существование ответственности за нарушение бюджетного законодательства и выделяют ее как своего рода самостоятельную финансовую ответственность.

В настоящее время Бюджетный кодекс РФ не содержит понятия «бюджетное правонарушение», вместо него используется понятие «бюджетное нарушение».

Основная задача бюджетной системы - создание финансовой базы для функционирования государства в целом, его субъектов и муниципальных образований. В процессе реализации данной функции нередко выявляются бюджетные нарушения.

Так, нарушение бюджетного законодательства - это неисполнение либо ненадлежащее исполнение установленного Бюджетным кодексом РФ порядка составления и рассмотрения проектов бюджетов, утверждения бюджетов, исполнения и контроля за их исполнением.

Глава 29 Бюджетного кодекса Российской Федерации посвящена бюджетным нарушениям, которые в настоящее время представляют собой одну из важных проблем функционирования этой государственной системы. Закрепленный в статье 29 БК РФ 
принцип единства бюджетной системы Российской Федерации предполагает наличие единого бюджетного законодательства Российской Федерации, единых санкций за его нарушение.

Поэтому нормы, предусматривающие основание, порядок, принципы привлечения к бюджетно-правовой ответственности, могут устанавливаться исключительно на федеральном уровне. Привлечение к ответственности происходит в процессуальной форме, в определенном порядке.

В главе 30 Бюджетного Кодекса РФ перечислены виды бюджетных нарушений и бюджетные меры принуждения, применяемые за их совершение. Проанализируем и раскроем содержание названных выше нарушений:

1) нецелевое использование бюджетных средств, то есть направление средств бюджета бюджетной системы Российской Федерации и оплата денежных обязательств в целях, не соответствующих полностью или частично целям, определенным законом о бюджете, сводной бюджетной росписью, бюджетной росписью, бюджетной сметой, договором или иным документом, являющимся правовым основанием предоставления указанных средств. Оно влечет за собой передачу уполномоченному по соответствующему бюджету части полномочий главного распорядителя, распорядителя и получателя бюджетных средств, а также бесспорное взыскание суммы средств, полученных из другого бюджета бюджетной системы РФ;

2) невозврат либо несвоевременный возврат бюджетного кредита финансовыми органами, который влечет за собой бесспорное взыскание суммы непогашенного остатка бюджетного кредита и пеней за его несвоевременный возврат в размере одной трехсотой действующей ставки рефинансирования ЦБ РФ за каждый день просрочки и приостановление предоставления межбюджетных трансфертов бюджету, которому предоставлен бюджетный кредит, на сумму непогашенного остатка бюджетного кредита;

3) не перечисление либо несвоевременное перечисление финансовым органом платы за пользование бюджетным кредитом. Оно влечет за собой бесспорное взыскание суммы платы за пользование бюджетным кредитом и пеней за ее несвоевременное перечисление в размере одной трехсотой действующей ставки рефинансирования ЦБ РФ за каждый день просрочки и приостановление предоставления межбюджетных трансфертов бюджету, которому предоставлен бюджетный кредит, на сумму непогашенного остатка платы за пользование бюджетным кредитом;

4) нарушение финансовым органом условий предоставления бюджетного кредита, который предоставлен одному бюджету бюджетной системы Российской Федерации из другого бюджета бюджетной системы Российской Федерации, при условии, что это действие не связано с нецелевым использованием бюджетных средств, влечет бесспорное взыскание суммы средств, использованных с нарушением условий предоставления бюджетного кредита, и платы за пользование ими и приостановление предоставления межбюджетных трансфертов (за исключением субвенций);

5) нарушение финансовым органом и получателем средств бюджета, условий предоставления межбюджетных трансфертов, в том случае, если это действие не связано с нецелевым использованием бюджетных средств, влечет бесспорное взыскание суммы средств, использованных с нарушением условий предоставления межбюджетного трансферта, и приостановление предоставления межбюджетных трансфертов.

Правовая основа применения мер принуждения за их совершение, так же как статус участников правоотношений, закрепляется Бюджетным кодексом РФ.

На основании ст. 306.1 БК РФ бюджетное нарушение рассматривается как совершенное высшим исполнительным органом государственной власти субъекта 
Российской Федерации, финансовым органом (органом управления государственным внебюджетным фондом), главным администратором бюджетных средств, государственным (муниципальным) заказчиком:

- если нарушили положения бюджетного законодательства РФ и иных правовых актов, регулирующих бюджетные правоотношения;

- если нарушили положения правовых актов, которые повлекли за собой причинение ущерба публично-правовому образованию;

- если нарушили условия договоров (соглашений) о предоставлении средств из бюджета;

- если нарушили условия государственных контрактов.

При наступлении финансово-правовой ответственности применяются санкции, которые предусмотрены Бюджетным кодексом Российской Федерации. Совершение бюджетного нарушения, предусмотренного главой 30 БК РФ, влечет применение бюджетной меры принуждения на основании уведомления о применении бюджетных мер принуждения органа государственного (муниципального) финансового контроля.

Так, в случае совершения правонарушения участником бюджетного процесса предусматривается применение мер принуждения, закрепленных в статье 306.2 Бюджетного кодекса РФ. Данные санкции могут применяться в случае не только нарушения каких-либо норм, но и в виде мер, обеспечивающих компенсацию потерь государственных финансовых фондов [4, ст. 102].

Как отмечает Л.А. Драгунова, с которой следует согласиться, «главная задача бюджетного законодательства состоит в том, чтобы установить систему адекватных мер ответственности в области бюджетных отношений» [5, 77]. В.С. Карнович подчеркивает, что «ответственность за нарушения бюджетного законодательства заключается в определенных лишениях личного, имущественного или организационного характера, которые претерпевает нарушитель» [6, с. 116].

Однако, некоторые вопросы привлечения к ответственности за нарушение бюджетного законодательства до сих пор не решены. В частности, те составы бюджетных нарушений, за которые прежде устанавливалась ответственность, теперь не относятся к бюджетным нарушениям. Соответственно к лицам, совершившим эти нарушения, неприменимы меры бюджетного принуждения.

Наиболее проблемным является вопрос о виновности как признаке бюджетного правонарушения. 3.А. Арсланбекова отмечает, что «бюджетное законодательство не всегда указывает на виновность как обязательный признак привлечения к бюджетной ответственности» [3, с. 115]. В свою очередь, Н.А. Саттарова подчеркивает, что «бюджетное законодательство не содержит указаний на виновность правонарушителя, однако его вина предполагается» [9, с. 126].

Вина может быть умышленной и неосторожной, вследствие чего бюджетное нарушение может совершаться либо умышленно, либо по неосторожности. Например, нецелевое использование бюджетных средств, а также их несвоевременный возврат могут совершаться лишь в форме умысла или неосторожности. Отсутствие вины в деяниях лица, не выполнившего бюджетную обязанность, указывает на отсутствие нарушения, в связи с чем такое лицо не несет юридической ответственности. Значит, наступление бюджетной ответственности возможно также при отсутствии субъективной стороны состава бюджетного нарушения.

Такой подход законодателя представляется не вполне правильным. Нельзя также согласиться с учеными, считающими, что вина не имеет значения при применении мер принуждения. Думается, что большинство бюджетных нарушений совершается виновно, например нецелевое использование бюджетных средств, финансирование расходов сверх утвержденных лимитов и другие.

Проблема повышения ответственности за нарушение бюджетного законодательства в настоящее время относится к числу острейших проблем функционирования 
бюджетной системы. Как подчеркивает М.Ю. Роман, «это результат отсутствия эффективного контроля, выявления и последовательного привлечения к ответственности за бюджетные правонарушения, в том числе и отсутствие реальной системы предупреждения» [8, с. 284].

Аналогичного мнения придерживается Л.А. Драгунова, считая важной причиной нарушения бюджетного законодательства «отсутствие эффективного механизма принуждения за нарушения бюджетного законодательства, а также бессистемность положений о финансовом контроле в Бюджетном кодексе Российской Федерации» [5, с. 80]. Поэтому, как представляется, надо повысить эффективность существующих мер ответственности в рассматриваемой сфере как одного из наиболее важных институтов бюджетного права.

Таким образом, можно сказать, что проблема разграничения финансово-правовой и административной ответственности является сложным процессом, т.к. отсутствует разделение данных видов правонарушений на законодательном уровне.

Вопрос о выделении бюджетно-правовой ответственности в самостоятельный вид ответственности достаточно сложный и спорный.

Вопросы об институте бюджетно-правовой ответственности напрямую зависит от точки зрения исследователей по вопросу об отраслевых границах и месте административного, финансового и налогового права в правовой системе. Взяв во внимание данную особенность, следует различать три точки зрения по вопросу бюджетной ответственности.

Первая точка зрения включает в себя ученых по административному праву (Д. Бахрах, Л.А. Калинина). У данных ученых превалирует мнение о том, что финансовое право возникло путем деления из административного права, и они считают административное право преобладающим правом. Так же они считают, что область финансово-правового регулирования отнесена к предмету административного права.

Вторая точка зрения включает в себя специалистов по финансовому (бюджетному) праву (Е.Ю. Грачева, М.В. Карасева). Данные специалисты рассматривают бюджетную ответственность как разновидность финансовой ответственности.

Третья точка зрения включает в себя ученых (А.В. Брызгалин, А.В. Зимин), у которых с одной стороны не указывается мнение автора о степени обособленности налогового права от финансового, но с другой стороны, бюджетная ответственность рассматривается в качестве разновидности административной ответственности.

По мнению Э.С. Карпова, анализ признаков бюджетно-правовой ответственности позволяет сделать вывод о том, что она наряду с уголовной или административной ответственностью имеет абсолютно все закрепленные в законе признаки и элементы юридической ответственности, и поэтому, фактически выступает в качестве самостоятельного вида юридической ответственности.

Рассмотрев различные точки зрения авторов, мы пришли к выводу о том, что бюджетно-правовая ответственность считается разновидностью государственного принуждения, которое регулируется бюджетно-правовыми нормами. Отталкиваясь от этого, можно вывести такие признаки бюджетно-правовой ответственности, как:

— наличие определенной сферы применения - бюджетный процесс.

- специфический судебный состав: участники бюджетного процесса.

Отметим, что мнения авторов сходятся в том, что бюджетно-правовая ответственность не имеет права претендовать на роль самостоятельного вида юридической ответственности.

Ее следует рассматривать как разновидность финансовой ответственности, а не как самостоятельный вид юридической ответственности, так как бюджетное право не является самостоятельной отраслью права, но, несмотря на это, создается видимость 
выделения бюджетно-правовой ответственности из-за достаточных признаков юридической ответственности.

$$
* * *
$$

1. Бюджетный кодекс Российской Федерации от 31.07.1998 № 145-Ф3 (ред. от 01.07.2021, с изм. от 15.07.2021) (с изм. и доп., вступ. в силу с 12.07.2021) // Собрание законодательства РФ. - 1998. № $31 .-$ Ст. 3823.

2. Кодекс Российской Федерации об административных правонарушениях от 30.12.2001 № 195-Ф3 (ред. от 01.07.2021) // Собрание законодательства РФ. - 2002. - № 1 (ч. 1). - Ст. 1.

3. Арсланбекова А.З. Проблемы применения ответственности за нарушение бюджетного законодательства // Право и политика. - 2019. - № 9. - С. 113-119.

4. Бортник И.В. Ответственность за нарушение финансового законодательства: правовой анализ норм // Legal Bulletin. - 2020. -T. 5, № 1. - C. 101-107.

5. Драгунова Л.А. Проблемы привлечения к ответственности за нарушение бюджетного законодательства Российской Федерации // Правоприменительная дея-тельность: история и

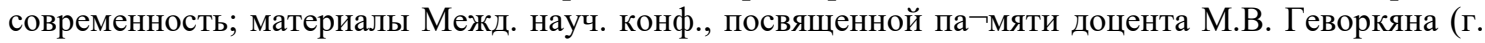
Псков, 27 июня 2017 г.). - Псков, 2017. - С. 76-83.

6. Карнович В.С. Основания наступления ответственности за нарушения бюд жжетного законодательства // Наука и инновации в XXI веке: актуальные вопросы, отาкрытия и достижения; сб. ст. V Межд. науч.-практ. конф.: в 2 ч. (г. Пенза, 5 августа 2017 г.). - Пенза: Наука и Просвещение, 2017. - С. 115-118.

7. Наумов А.В. Российское уголовное право. Курс лекций. Т. Общая часть. 4-е изд. - М., 2019. C.406

8. Роман М.Ю. Теоретико-правовые основы юридической ответственности за нарушение бюджетного законодательства // Правовая безопасность личности, государ ᄀства и общества: сб. ст. XIX Межд. науч. конф. (г. Москва, 25 апреля 2019 г.) / под ред. Н.И. Архиповой, С.В. Тимофеева, Е.Ю. Князевой. - М., 2019. - С. 283-289.

9. Саттарова Н.А. Принуждение в финансовом праве / под ред. проф. И.И. Кулчерова. - М.: Юрлитинформ, 2020. - С. 126.

\section{Стрыгина C.B. \\ Соотношение социальной и экологической ответственности предпринимателей}

Саратовский национальный исследовательский государственный университет им. Н.Г. Чернышевского

doi: $10.18411 / \mathrm{j}-08-2021-141$

(Россия, Саратов)

\section{Аннотация}

В статье речь идет о необходимости сочетания социальной и экологической ответственности бизнеса в условиях глобальных экологических проблем. Анализируются документы, разработанные на международном и национальном уровне, о сущности и содержании социальной ответственности. Приводится эмпирический материал по внедрению новых технологий в стране и за рубежом, имеющих социальное значение. Указываются причины отсутствия в стране модели корпоративной социальной ответственности.

Ключевые слова: социальная ответственность, экология, устойчивое развитие, стандарты, новые технологии, зеленая экономика, безопасное производство.

\section{Abstract}

The article deals with the need to combine the social and environmental responsibility of business in the context of global environmental problems. The documents developed at the international and national level on social responsibility are analyzed. The empirical material on the introduction of new technologies in the country and abroad, which are of social importance, is presented. The reasons for the absence of a model of corporate social responsibility in the country are indicated.

Keywords: social responsibility, ecology, sustainable development, standards, new technologies, green economy, safe production. 